\section{Combining clinical and molecular heterogeneity within CASPR2-antibody mediated diseases: towards the underlying disease biology}

\author{
Sophie Binks, Sarosh R Irani
}

Muñiz-Castrillo aims towards precision medicine in CASPR2-antibody diseases by dissecting clinical features, serology and genetics across 56 patients.

Since their description in $2010,{ }^{1}$ the spectrum of clinical features associated with CASPR2-antibodies has evolved. Today, cramps, neuropathic pain, hyperhidrosis, hypertension, seizures, cognitive impairment, psychiatric features and cerebellar ataxia are all recognised associations. ${ }^{2-4}$ This clinical diversity has intensified with the interweaving of increasingly broad observations regarding patient demographics and tumour status. ${ }^{3}$ One method to deconvolute clinical boundaries is to use the fundamental biology as a gold standard for classification. In the paper by Muñiz-Castrillo, the authors explain the complexity underlying the CASPR2antibody diseases using a data-driven approach to phenotyping, in parallel with immunological and genetic markers integral to disease pathogenesis. ${ }^{5}$

By cluster analysis, 56 patients with CASPR2-antibodies were divided into four groups: (i) a relatively isolated limbic encephalitis (LE) ('LE/-'; $n=18$ ), (ii) LE 'plus' non-limbic symptoms, including cerebellar ataxia, movement disorders, dysautonomia and weight loss ('LE/t'; $\mathrm{n}=11$ ), (iii) a group with severe peripheral nerve hyperexcitability (PNH), plus dysautonomia, dyssomnia and malignant thymoma, but without limbic featuresclosely resembling contemporary descriptions of Morvan's syndrome ('PNH/+'; $\mathrm{n}=16)^{2}$ and (iv) a less severe form of PNH with only few associated central nervous system (CNS) features ('PNH/-'; $n=11$ ). These phenotypes explained some of the variance observed across paraclinical findings, such as inflammation on MRI/cerebrospinal fluid (CSF). Yet, it is unclear whether these groups will accommodate all CASPR2-antibody presentations, such

Oxford Autoimmune Neurology Group, Nuffield Department of Clinical Neurosciences, University of Oxford, Oxford, UK

Correspondence to Dr Sarosh R Irani, Oxford Autoimmune Neurology Group, Nuffield Dept of Clinical Neurosciences, University of Oxford, Oxford, UK; sarosh. irani@ndcn.ox.ac.uk as those who present with limited cognitive impairment but a prominent movement disorder.

Nevertheless, these groups showed marked differences in autoantibody profiles. For example, CSF CASPR2antibodies were detected in 27/29 patients from the two LE groups but only 4/7 with $\mathrm{PNH} /-$ and, perhaps surprisingly, 0/12 with $\mathrm{PNH} /+$. Such absence of detectable CSF CASPR2-antibodies in patients with CNS-localisable features may represent an emerging theme in the field. ${ }^{3}$ A similar trend was observed for serum CASPR2antibody levels: these were highest in both $\mathrm{LE}$ groups $>\mathrm{PNH} /+>\mathrm{PNH} /-$. Co-existent LGI1-antibodies were only detected in the $\mathrm{PNH} /+$ patients with a malignant thymoma, a finding which may usefully help accurately identify a paraneoplastic subgroup. $^{26}$

Finally, the human leucocyte antigen (HLA) genotypes of 30 patients were analysed and yielded the most categorical result. HLA-DRB1*11:01 was first identified in 2018 as a risk allele in $15 / 31(48 \%)$ of patients with CASPR2antibodies, alongside an extended haplotype. ${ }^{6}$ Now, Muñiz-Castrillo et al show HLA-DRB1*11:01 is present in 93\% $(16 / 17)$ of genotyped LE cases (both LE/and $\mathrm{LE} /+$ ), but observed at rates equivalent to healthy controls in the $\mathrm{PNH} /+$ and $\mathrm{PNH} /$ - patients. Hence, with a frequency akin to HLA-DRB1*07:01 in patients with LGI1-antibodies, ${ }^{6}$ a single allelic HLA association of CASPR2-antibodies in CNS diseases may almost be the rule. ${ }^{7}$ This finding now awaits confirmation: analysis of our published cases showed a less striking bias given 13/22 (59\%) with exclusive CNS features carried HLADRB1*11:01, compared with 2/5 (40\%) with $\mathrm{PNH}^{+/}$.

Despite incomplete data sets for some patients, Muñiz-Castrillo et al illustrate a simple yet elegant method to use the fundamental biology to (re)define the clinical syndrome. The principal serological and genetic segregations were observed between patients with and without $\mathrm{PNH}$. This 'take home point' largely returns to traditional CASPR2-antbody associated syndromic categorisations: $\mathrm{PNH}$, Morvan's syndrome and LE. Moreover, it suggests that the mechanism of the autoimmunisation required to generate CASPR2antibodies may determine the clinical manifestations and the presence or absence of CSF CASPR2-antibodies. More practically, adjunctive HLA-testing could help introduce precision-medicine to the autoimmune neurology clinic and reinforce observations suggesting genotyping might indicate which CASPR2-antibody patients will be most immunotherapy-responsive. ${ }^{6}$

In conclusion, a fundamental immunogenetic distinction may underlie the localisation of CASPR2-antibody diseases. This important new insight is reminiscent of the reclassification prompted by refining the biochemistry which identified LGI1-antibodies and CASPR2-antibodies from the now clinically-redundant VGKC-antibody assay. ${ }^{8}$ Muñiz-Castrillo's finding should usher in fruitful new understanding of the biology of CASPR2antibody diseases, with future implications for pathogenesis and selection of immunotherapies.

Twitter Sarosh R Irani @ANG_Oxford

Contributors SRI and SB drafted and edited the manuscript.

Funding SRI is supported by the Wellcome Trust (104079/Z/14/Z), BMA Research Grants - 2013 Vera Down grant and 2017 Margaret Temple, Epilepsy Research UK (P1201) and by the Fulbright UK-US commission (MS-Research Society Award). SB is supported by the Wellcome Trust. The work is supported by the National Institute for Health Research (NIHR) Oxford Biomedical Research Centre (BRC). The views expressed are those of the authors and not necessarily those of the NHS, the NIHR or the Department of Health.

Competing interests SRI is a co-applicant and receives royalties on patent application WO/2010/046716 entitled 'Neurological Autoimmune Disorders'. The patent has been licensed to Euroimmun AG for the development of assays for LGI1 and other VGKC-complex antibodies. SRI and SB are coinventors on 'A Diagnostic Strategy to improve specificity of CASPR2 antibody detection.' Ref. JA94536P.

Patient consent for publication Not required.

Provenance and peer review Commissioned; internally peer reviewed.

\section{(2) OPEN ACCESS}

Open access This is an open access article distributed in accordance with the Creative Commons Attribution 4.0 Unported (CC BY 4.0) license, which permits others to copy, redistribute, remix, transform and build upon this work for any purpose, provided the original work 
is properly cited, a link to the licence is given, and indication of whether changes were made. See: https:// creativecommons.org/licenses/by/4.0/.

(C) Author(s) (or their employer(s)) 2020. Re-use permitted under CC BY. Published by BMJ.

\section{D) Check for updates}

To cite Binks S, Irani SR. J Neurol Neurosurg Psychiatry 2020;91:1033-1034.

Received 10 June 2020

Revised 19 June 2020

Accepted 22 June 2020

Published Online First 10 July 2020

\section{S Linked}

- http://dx.doi.org/10.1136/jnnp-2020-323226

J Neurol Neurosurg Psychiatry 2020;91:1033-1034. doi:10.1136/jnnp-2020-323457

ORCID iD

Sarosh R Irani http://orcid.org/0000-0002-7667-9748

\section{REFERENCES}

1 Irani SR, Alexander S, Waters P, et al. Antibodies to Kv1 potassium channel-complex proteins leucine-rich, glioma inactivated 1 protein and contactin-associated protein-2 in limbic encephalitis, Morvan's syndrome and acquired neuromyotonia. Brain 2010;133:2734-48.

2 Irani SR, Pettingill P, Kleopa KA, et al. Morvan syndrome: clinical and serological observations in 29 cases. Ann Neurol 2012:72:241-55.

3 Syrbe S, Stettner GM, Bally J, et al. Caspr2 autoimmunity in children expanding to mild encephalopathy with hypertension. Neurology 2020;94:e2290-301.
4 Binks SNM, Klein CJ, Waters P, et al. Lgi1, Caspr2 and related antibodies: a molecular evolution of the phenotypes. I Neurol Neurosurg Psychiatry 2018;89:526-34.

5 Muñiz-Castrillo S, Joubert B, Elsensohn M-H, et al. AntiCASPR2 clinical phenotypes correlate with HLA and immunological features. J Neurol Neurosurg Psychiatry 2020;91:1076-84

6 Binks S, Varley J, Lee W, et al. Distinct HLA associations of LGI1 and CASPR2-antibody diseases. Brain 2018:141:2263-71.

7 Dubey D, Britton J, McKeon A, et al. Randomized placebo-controlled trial of intravenous immunoglobulin in autoimmune LGI1/CASPR2 epilepsy. Ann Neurol 2020:87:313-23.

8 Lang B, Makuch M, Moloney T, et al. Intracellular and non-neuronal targets of voltage-gated potassium channel complex antibodies. J Neurol Neurosurg Psychiatry 2017;88:353-61. 